comparison so that scientists, industry and the public can make informed decisions about which chemicals are best.

Daniel Durham, who heads a chemicalassessment programme at the Houston-based energy company Apache, says that although Heine's effort is promising, companies do not need to wait. The US Environmental Protection Agency (EPA) already maintains its own public registry of preferred chemicals for various industrial processes. Companies that want to register their chemicals provide the EPA with toxicity and environmental-assessment data; the registry also allows companies to keep certain data confidential if intellectual property is involved.

The upshot is a growing - albeit incomplete - list of preferred chemicals that companies such as Apache can choose from as they design their fracking fluids. A company that wants to avoid using a solvent such as ethylene glycol monobutyl ether, for example - used to reduce viscosity but possibly toxic to the endocrine system - could look through the EPA list for alternatives. "It's a very good road map to green chemistry," Durham says.

Eventually, Durham hopes that researchers will help to develop novel chemicals that could be used to make the entire hydraulicfracturing process cleaner and more efficient.

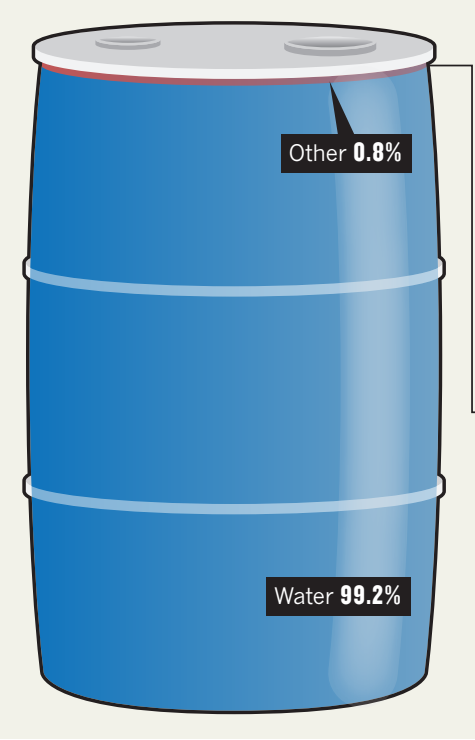

\section{A RECIPE FOR FRACKING}

Once a well has been drilled and sealed off, companies inject hydraulic fracturing fluids at high pressures to break up the rock and allow oil and gas to flow. These fluids, which are mostly water, are mixed with sand; this is used to prop fractures open. Acids dissolve minerals and initiate cracks. Gelling agents are used to suspend sand in the water, and breakers delay breakdown of the gels. Friction reducers lubricate the fissures. Pipes are protected by corrosion and scaling inhibitors, biocides and chemicals that control reactions with iron and clay.

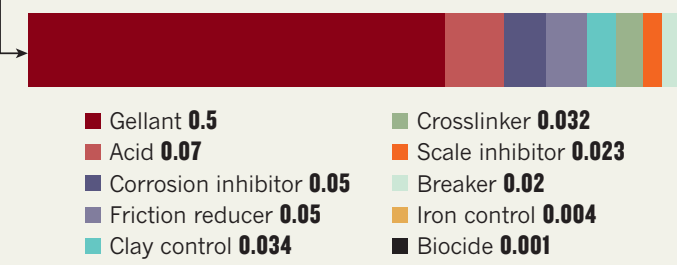

Scientists such as Ellis could play an important part.

Ellis wants to know whether fracking fluids are contributing to geochemical reactions within the shale rock that might free up potentially dangerous metals and radionuclides, such as arsenic, barium, strontium and uranium. These elements are often found in trace concentrations in the waste water produced by oil and gas companies, but can also be found naturally in groundwater. Ellis eventually hopes to help companies to select better chemicals that would minimize the potential for contamination and the need for wastewater treatment. But for now, he says, he is focused on the basic science. "Fundamentally, I just want to understand those reactions a little better." -

\title{
More cuts loom for US science
}

\section{Stalemate in Congress puts spending plans on hold.}

\section{BY LAUREN MORELLO}

$\mathrm{L}$ aura Niedernhofer is counting her pennies. The mid-career molecular biologist moved last year to the Scripps Research Institute's campus in Jupiter, Florida — a risky decision that saw her building a new laboratory group at a time when the US government was cutting its support for science. In June, Niedernhofer abandoned one of her main lines of research - reducing the toxicity of cancer drugs - after the National Institutes of Health (NIH) rejected her grant application. In July, the agency approved a second grant, allowing her to keep another research thrust alive - on the molecular mechanisms of ageing. But the NIH cut the award by $18 \%$, preventing her from hiring an additional postdoctoral researcher.

Niedernhofer is not alone. In a survey of more than 3,700 US scientists released on 29 August by the American Society for Biochemistry and Molecular Biology in Rockville, Maryland, onethird said that they had laid off researchers, and close to two-thirds had seen their funding fall

since 2010. Federal spending on research and development has declined by $16.3 \%$ since 2010 , the fastest drop in a three-year period since the end of the space race in the 1970s, according to an analysis published on 3 September by the American Association for the Advancement of Science in Washington DC.

The most drastic reduction occurred on 1 March, when across-the-board budget cuts known as sequestration lopped $5 \%$ from the budgets of most government agencies. Science

\section{"There is contimuing pressure for additional budget cuts as a price for raising the debt ceiling."} powerhouses such as the NIH in Bethesda, Maryland, and the National Science Foundation in Arlington, Virginia, began to scrimp by reducing the values and durations of grants, and the number of recipients per application cycle.

The situation could worsen in the coming months. Congress, which returned to Washington DC this week, has made little progress on setting government spending for the 2014 fiscal year, which begins on 1 October. An attempt by a group of Republican senators and the White House to negotiate an agreement on deficit reduction broke down in late August, and since then the crisis in Syria has diverted the attention of Congress. To avoid a government shutdown, lawmakers are expected to extend current funding levels until December. That extension, known as a continuing resolution, would run out at about the same time that the country confronts another financial matter: surpassing its borrowing limit, or debt ceiling.

That could set up a budget battle royal in the next few months. A similar fight in the summer of 2011 led to the law that created sequestration; it specifies annual spending reductions until 2021, if Congress does nothing to override it. The next round of cuts, scheduled to take effect in January 2014, would trim spending to $2 \%$ below the already-whittled-down 2013 level.

Indications of how the various science agencies will fare can be found in Congress's 
unfinished spending bills. The Democratic-controlled Senate would eliminate sequestration and give science agencies modest boosts. The Republican-controlled House of Representatives would cut funding in many areas to keep total spending in line with the $2 \%$ cut that sequestration prescribes. One relatively bright spot is the House's proposed allocation of $\$ 7.0$ billion for the National Science Foundation, the same amount that the agency received in 2012 - a bountiful level in House terms. But Barry Toiv, vice-president for public affairs at the Association of American Universities in Washington DC, worries that House Republicans will now end up seeking cuts beyond 2\%. "There is continuing pressure for additional budget cuts as a price for raising the debt ceiling," he says.

The situation leaves US research institutions in an uneasy position, unsure whether 2013 funding levels will have been the nadir, or a prelude to something worse. Many are just beginning to feel the effects, because of the delay between the sequestration cuts and grants being awarded. At the University of Maryland in College Park, the haul of grants from the $\mathrm{NIH}$ was $7 \%$ below projections in the 2012-13 academic year, and its share of defence-department cash was 3\% lower than expected, says chief research officer Patrick O'Shea. At Johns Hopkins University in Baltimore, Maryland, four doctoral programmes in the department for environmental health sciences each accepted just one student this year, instead of the usual two or three, says Jonathan Links, a medical physicist who handles the university's crisis planning.

But US universities collect tuition fees and generally have endowments, which means that they have ways to provide stopgap funding to scientists in tight spots. At a 'soft-money' research institute such as Scripps, grants are needed to pay almost all the bills - so Niedernhofer's situation was more dire.

Although she is continuing her ageing research with her three postdocs, she has a new standard question she asks before hiring them: will they consider only academic research as a job? "I can't guarantee that they will get that," she says, "and I don't want to be the one to break their hearts." -

\title{
PHYSICS
}

\section{Ultimate upgrade for US synchrotron}

\author{
Argonne lab banks on beam-bending magnets in bid for \\ world's most focused $X$-ray light source.
}

\section{BY EUGENIE SAMUEL REICH}

$\mathrm{E}$ very day, in dozens of synchrotrons around the globe, electrons are whipped around in circular storage rings to provoke them into emitting X-rays, useful for imaging materials, identifying chemical-reaction products and determining crystal structures.

But photon scientists do not want just any old storage ring. For more than a decade, they have dreamt of 'ultimate' storage rings ones that use specialized magnets to produce $\mathrm{X}$-ray beams that are as tightly focused as theory allows.

Now, researchers at the largest US synchrotron, the Advanced Photon Source (APS) at the Argonne National Laboratory in Illinois, are taking steps to develop this technology. In the process, they hope to leapfrog several international facilities that have a head start.

In Sweden, ultimate-storage-ring technology is being pioneered at MAX IV, a 528-metrecircumference synchrotron in Lund. Scientists there first sought to increase the intensity and brightness of the synchrotron's X-ray light in 2006 by focusing electron beams more tightly. The design relied on groups of seven magnets, known as multi-bend achromats, that could be used in as many as 20 places around the ring to nudge the paths of electrons back and forth until they lined up more-or-less perfectly. Machine director Mikael Eriksson recalls that when he toured US light sources to describe the project, "few believed it".

Eriksson now has believers. In a report posted online on 29 August, researchers at the Argonne lab describe how they are hoping to upgrade the 1.1-kilometre-circumference APS with multi-

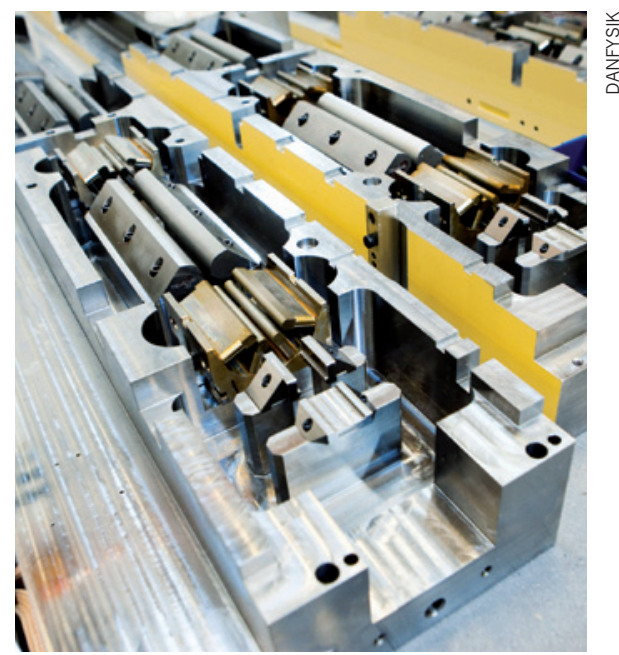

Magnets for the Swedish MAX IV synchrotron.

bend achromats (see go.nature.com/asxrqb). "There's a new technology that has come along and it's pretty revolutionary," says APS director Brian Stephenson. Current storage rings have at most double-bend achromats, which contain two magnets rather than seven. Physicists had thought that including more magnets would make the beam unstable by bending it too much and introducing too many fluctuations. But the work at MAX IV showed that very compact magnets enable bending paths that are short enough to stop fluctuations from building up.

The US Department of Energy, which funds the APS, still needs to approve the plan. In July, one of the department's advisory committees suggested that US labs were being left behind while other countries push towards ultimate storage rings. The committee had also recommended pursuing a next-generation X-ray

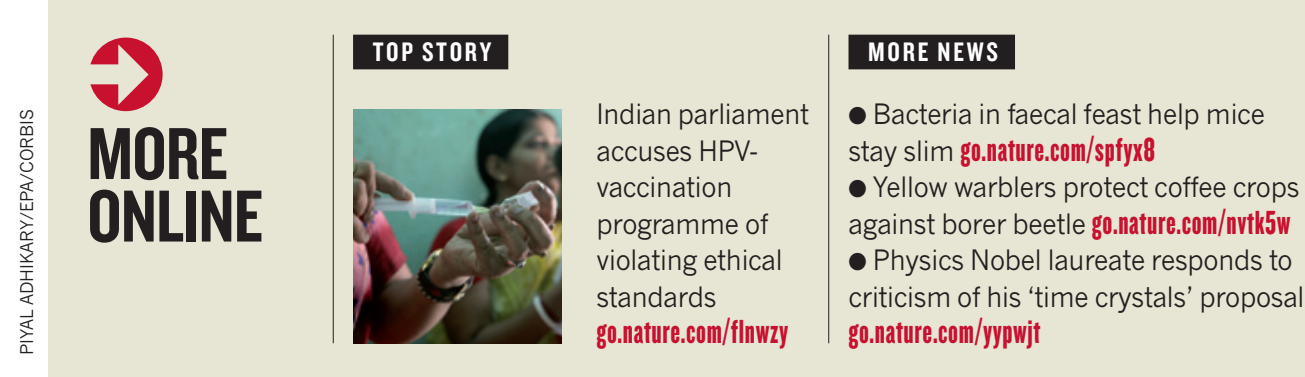

\section{IMAGE OF THE WEEK}

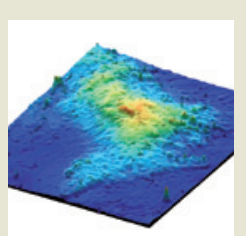

Volcano found under Pacific Ocean is Earth's largest at 650 kilometres wide go.nature.com/ beeqp 4 